\title{
ПОВЕСТВОВАТЕЛЬНЫЙ ФОЛЬКЛОР
}

УДК 398.1 (=512)+398.223

DOI 10.25205/2312-6337-2019-1-53-61

\author{
Е. В. Королёва \\ Научно-методический центр «Сибирь»

\section{Этническая самоидентификация алтай-кижи в контексте устных исторических преданий}

Статья посвящена анализу этномаркирующих и интеграционных сюжетов алтайских исторических преданий. Автор характеризует историческую специфику формирования корпуса алтайских исторических преданий, предпринимает попытку систематизировать сюжеты по содержанию и выделяет признаки этнической идентичности для алтай-кижи на основе фольклорных текстов: язык, образ жизни, тип хозяйствования, одежда, прическа. Подробно описаны этапы интеграции мигрантов в состав структуры экзогамных родов у алтай-кижи на примере текстов преданий. Поставлен вопрос о билингвальном бытовании алтайских фольклорных текстов. Отмечена актуальность исторических преданий в современном сообществе.

Ключевые слова: Алтай, алтайцы, алтайские исторические предания, устная история, этническая история, Ойротский каганат, гражданская война, этническая идентификация, инкорпорация иноплеменников, реконструкция системы экзогамных родов..

Алтайские исторические предания (озогы-куучиндар) входят в состав корпуса жанров народной литературы, воссоздаются и активно пересказываются по сей день как на алтайском, так и на русском языках. Проблеме разграничения жанров, специфике распространения и воспроизводства, а также религиозной (бурханисткой) составляющей данных фольклорных текстов мы уже уделяли внимание ранее [Королёва, 2015]. Настоящая статья посвящена историческим преданиям как инструменту конструирования этнического самосознания. Использованные тексты были извлечены из личного полевого архива автора (2001-2011 гг.), собраний Б. Я. Бедюрова [Озогы Тйӱкилер, 2011], в переводе и подготовке к изданию которого автор участвует начиная с 2014 г. [Алтайские исторические предания, 2014; Бедюров, 2017], а также билингивистического издания из академической серии «Памятники фольклора народов Сибири и Дальнего Востока» [Несказочная проза алтайцев, 2011].

Стартовой точкой для массива текстов алтайских исторических преданий являются события позднего периода истории Ойротского (Джунгарского) ханства: гражданская война 1745-1754 гг. и маньчжурская (Цинская) интервенция 1755-1759 гг., спасение народа в лоне Алтайских гор и вхождение в состав Российской империи. Распад государства Ойрот-Каана на фоне противоборства претендентов на престол - Табачы (Дабачы) и Амыр-Саны с последующим вторжением армии Цинской империи описывается в преданиях как эсхатологическое событие - чак ${ }^{1}$. Гражданская война, развязанная на-

\footnotetext{
${ }^{1}$ Чак - «крах», буддийский по происхождению термин, обозначающий разрушительные события, неизменно сопровождающие смену кальп (эпох): стихийные бедствия, войны, эпидемии.

Королёва Елена Владимировна - научный сотрудник АНО Научно-методического центра «Сибирь» (Новосибирск).

Контактная информация: ул. Советская, д. 30, оф. 216, г. Новосибирск, 630099, Российская Федерация.

E-mail: e.v.koroleva@inbox.ru; тел.: +7-913-744-32-06.
}

ISSN 2312-6337. Языки и фольклор коренных народов Сибири. 2019. № 1 (37). С. 53-61.

(C) Е. В. Королёва, 2019. 
следниками, политика геноцида со стороны императора Канси, захватнические набеги на протяжении более чем 20 лет и депопуляция [Моисеев, 1983], а также массовые миграции привели к тому, что этнические самосознание алтайцев взросло на осколках ойротской исторической памяти и включает совокупность семейных преданий всех уцелевших представителей различных тюрко-монгольских этнических групп, родов и безвестных сирот. Возврат к мирной жизни и восстановление численности в течение XIX-XX вв. описываются как процесс воссоздания утраченного миропорядка, который в логике предания должен быть ознаменован возвращением Ойрот-Каана (возрождением государства). Не случайно вплоть до 1948 г. для обозначения коренного населения использовался этнонимполитоним «ойрот», который был ликвидирован из официальных документов по авторитарному политическому решению, предположительно, связанному с репрессиями в отношении калмыков.

Формирование нового этноса на пепелище гражданской войны требует решения непростой задачи: интеграции семейных преданий бывших политических противников и беженцев в состав массива общей исторической памяти. Алтайская народная литература по-своему решает этот вопрос, превращая исторических персонажей в литературных героев, носящих значимые имена и действующих в русле традиционных сюжетных линий. Другим путем является избегание некоторых конфликтных тем. Существуют косвенные признаки и прямые свидетельства респондентов о наличии «белых пятен» (зон умолчания) как в преданиях о событиях гражданской войны [Королёва, 2018], так и о более ранних перипетиях ойротской истории [Анохин, 1924, с. 23]. Не случайно количество записей преданий о противостоянии интервентам существенно превышает количество записей о противоборстве внутри ойротской державы (соотношение 10 к 1). Следует принимать во внимание также значительное сокращение этнической территории, потерю прежних кочевий для потомков ойротов или переселение на новые земли для потомков беженцев (например, енисейских кыргызов и сойонов). Значимые маркеры территории: прежние родовые кочевья, священные вершины, реки, останцы-межелики, поселения и могилы предков остались для многих вне зоны доступа и со временем были заново обретены на территории Горного Алтая. Исторические предания алтайцев отражают этот непростой и далеко не завершенный процесс формирования этнического самосознания в новых географических и политических границах.

На данный момент в исследовательской литературе существуют различные оценки состояния алтайского этноса и его взаимоотношений с другими субэтническими и этническими группами Южной Сибири [Чемчиева, 2017]. В работе над переводом с алтайского фольклорных текстов автор неоднократно сталкивался с многозначностью термина «Алтай», который в зависимости от контекста обозначает малую родину (место рождения), родную страну / край / регион, обитаемую людьми землю (ойкумену), мир живых. Таким образом, алтай-кижи в зависимости от контекста можно перевести как «свой человек», «живой человек», «человек с Алтая». Этот термин используется рассказчиками синонимично с алтайлар, алтай албаты и тождественен русскому «алтаец», в отличие от многочисленных локальных чуй-кижи, оймон-кижи, улан-кижи, которые можно перевести соответственно как «чуец», «оймонец», «улаганец». Последние являются не этнонимами, но катойконимами, в отличие от алтай-кижи, который наряду с алтай албаты служит для обозначения сообщества тюркоязычного населения, уцелевшего на пепелище Ойротской гражданской войны и объединенного наследием исторической памяти, языком и способом хозяйствования на территории Русского Алтая. Поэтому мы согласны с А. Чемчиевой в том, что противопоставление и обособление теленгитов чуй-кижи и алтай-кижи в значительной мере создано искусственно на основе политического акта «самоопределения» коренного малочисленного народа в сугубо экономических интересах на фоне исторически обусловленной специфики интеграционных процессов у потомков «двоеданцев» и «кан-каракольских калмыков». Мы также согласны с Л. И. Шерстовой, отмечающей, что в составе советских и постсоветских административных образований более многочисленные и активные алтай-кижи постепенно втягивают в свою орбиту и инкорпорируют в качестве субэтносов малочисленные этнические группы северных алтайцев: челканду, туба, куманды. Поэтому здесь и далее мы будем использовать тексты, записанные в Кош-Агачском районе среди чуй-кижи, равно как и в других районах Республики Алтай, как «алтайские» и рассматривать зафиксированную ими информацию как часть этнокультурного наследия алтай-кижи [Шерстова, 2005].

Интересной исследовательской проблемой представляется утеря на протяжении XIX в. свободного владения монгольским (ойротским) языком после более чем 300-летнего тюрко-монгольского двуязычия на Алтае, что может быть связано с длительным периодом разграничения территории, которая вплоть до закрепления границ по Чугучакскому договору оставалась спорной. Отвергая цинские претензии на овладение «ойротским наследством», население избегало открытого использования ойротского языка. Одновременно происходило освоение нового государственного (русского) языка, 
описанное в предании «Гнездо Кульди», что закономерно привело к середине XX в. к активному русско-алтайскому двуязычию у коренного населения и вытеснению алтайского языка из обихода русских старожильческих групп. Словарный состав и двуязычные топонимы свидетельствуют о том, что ранние «ойротские» сюжеты (XVII-XVIII вв.) пересказывались на алтайском (тюркском) и ойротском (монгольском) языках, в то время как более поздние (XIX-XX вв.) воспроизводились преимущественно на алтайском (тюркском). Таким образом, формирование корпуса преданий шло параллельно с языковой демаркацией.

Самый ранний перевод алтайских исторических преданий на русский язык мы фиксируем в конце XIX - начале XX в. в среде двуязычной старожильческой группы староверов - «оймонов» [Королёва, 2012]. Примерно с середины XX в. можно уверенно говорить о параллельном бытовании текстов преданий как на алтайском, так и на русском языках, что связано с образовательной политикой в $\mathrm{CCCP}$, а также с ростом интереса к краеведческой тематике в прессе, широкой публикации некоторых фольклорных материалов, что нередко приводило к публичной полемике среди респондентов [Алтайские исторические предания, с. 111-113, 114-119]. В настоящее время переводчик фольклорных текстов является ретранслятором традиции для той части алтайской молодежи, которая уже не владеет свободно алтайским языком. Например, переводчик эпоса «Маадай-Кара» Александр Плитченко посмертно становится легендарной фигурой в алтайской среде и фактически оказывается в одном ряду со сказителями кайчы и знающими людьми неме билер кижи, а также «приобретает» по отцовской линии «необходимое» родство с алтайским народом (Полевые материалы Е.В. Королёвой).

Сюжетная тематика исторических преданий включает:

- предания о героях (Ойрот-Каан, Шуну-Баатыр, Ярынак, Мооныш, Амыр-Сана, Юскюс-Уул и другие), сохраняющие имена и подвиги участников Ойротской войны в стилистике литературной традиции тюрко-монгольских народов (баaтыр сохраняет свой статус вне зависимости от принадлежности к стороне конфликта);

- истории о бёекёлерах (Ирбисек, Кёрёгёш, Бёкё-Самудай, Эркин-Оол и др.), повествующие о борцах - героях мирных времен, а также о переходе военных конфликтов с соседями в формат спортивных состязаний;

- интегращионные сюжеты, воспроизводящие подробные родословные крупных семей-гнёзд, подчеркивающие участие членов семьи в известных исторических событиях, а также описывающие происхождение родов (сӧӧк) и их ответвлений, в том числе и от суразов ${ }^{2}$, сирот, безвестных мигрантов, воссоздающие традиционную структуру экзогамных родов для новой этнической территории, обеспечивая инкорпорацию разнородных по происхождению семейных линий;

- топонимические сюжеты, включающие в пространство культурной традиции объекты ландшафта новой этнической территории;

- этномаркирующие сюжеты, описывающие предпочтительные модели поведения этноса, тип хозяйствования, семейного устройства, этические нормы и этикет.

Все без исключения исторические предания вне зависимости от тематики играют важную роль в формировании этнической идентичности алтайского народа: несут свидетельства «освоения» территории, фиксируют предпочтительные модели поведения и механизмы этнической инкорпорации, обозначают этнические границы в режиме оппозиции «свой-чужой», транслируют популярные концепты прошлого и модели будущего. Описанию специфики процесса превращения воспоминаний о героическом и темном прошлом в исторические предания (и образцы народной литературы) мы посвящали публикации ранее [Королёва, 2018]. В данной статье нам представляется важным привести конкретные примеры интеграционных и этномаркирующих мотивов и сюжетов, которые фиксируют признаки принадлежности героя к сообществу «людей Алтая» (алтай-кижи) и моделируют границы этого этноса.

Предание «Тонужаан карындаштар» («Братья из рода Тонгужаан») [Озогы Тӱӱкилер, 2011, с. 206210 ; Бедюров, 2017, с. 305-308] имеет в своей основе интеграционный сюжет и содержит несколько этномаркирующих мотивов. Повествование начинается и заканчивается восхвалением родины рассказчика Такая Тадянова - Яйлугуша: «у подножия вершины с белоснежным сумером, окруженным бело-голубыми полянами, вольготно пасется и размножается скот» [Бедюров, 2017, с. 305]. Некие три брата (уч кырындаштар) из рода тонгужаан, в годину бедствий скитаясь по Уралу после смерти родителей, встречают старика из рода иркит, который объясняет юношам, что им необходимо вернуться на родину - в бело-голубой Алтай. Братья следуют совету и спустя время добираются до Маймы-

\footnotetext{
${ }^{2}$ Сураз - «бастард», ребенок, рожденный вне брака, чей отец, а следовательно сёёк (экзогамный род), неизвестны.
} 
Чергачак, где их пути расходятся: один отправляется в чернёвую тайгу Аба-Йыш, где роднится с туба и ассимилируется среди них, другой - в Оймон, где обретает семью в среде русских староверов, а третий поселяется в Яйлугуше, где, занимаясь охотой и скотоводством, продолжает свой род среди алтайского народа (алтайлар, алтай албаты). Рассказчик подчеркивает, что на фронт Великой Отечественной войны отправилось 30 алтайцев-призывников тонгужаанов, что осмысливает как долг чести, свидетельство состоятельности рода и, одновременно, правильности выбора легендарного предка.

Данная история может быть отнесена к циклу преданий о происхождении экзогамных родов (сӧӧк), поясняющих, как и когда представители конкретного рода появились в конкретной местности, а также повествующих о родоначальниках и предках. Из контекста не ясно, были ли братья тонгужааны кровными родственниками или братьями «по кости» (сёёку). Примечательно, что для беседы со старцем-иркитом неизвестного происхождения на Урале, а также с жителями Майма-Чаргачак и представителями народности туба героям было достаточно знания родного языка, а вот для общения с оймонами нужен был неродной русский. Так или иначе все трое успешно инкорпорировались и продолжили род (сӧӧ), однако лишь один из них - тот, кто избрал Яйлугуш, сохраняет самосознание и образ жизни алтай албаты на вновь обретенной родине, что в тексте оформлено высказыванием алmaйга јурт тӧзӧгӧн 'своим алтаем сделать' [Озогы Тӱӱкилер, 2011, с. 208]. Отсюда видно, что ни язык, ни родовая принадлежность сами по себе не являются основополагающими признаками этнического самоопределения с точки зрения рассказчика, но становятся таковыми только в совокупности с сохранением традиционного типа природопользования (яйлажного скотоводства и охоты). Между тем система экзогамных родов легко перешагивает этнические границы и в определенной степени становится фактором гармонизации межэтнических взаимоотношений на данной территории. Комплексный анализ и теоретическое осмысление феномена сёёка как «вторичного рода» находятся в работе Л. И. Шерстовой [2005], мы же описывали его в среде старообрядцев-оймонов [Королёва, 2012, 2015].

Принципы этнической демаркации с русскоязычными и инаковерующими оймонами понятны, но как быть с родственными и тюркоязычными туба? Возможно, предание о братьях тонгужаанах объясняет нам, что настороженное пограничное отношение к туба, которое фиксируют современные исследователи [Шерстова, 2005], коренится не столько в более высоком уровне русификации данной этнической группы, сколько в специфике традиционной экологической ниши подтаежных охотников и собирателей, находящейся за границами территории, благоприятной для яйлажного скотоводства ключевого, системообразующего типа природопользования для Ойротского каганата и государствпредшественников. Степень вовлеченности в государственное строительство и, соответственно, социальный статус алтайлар или алтай-кижи Яйлугуша и туба был и остается различным. Складывается впечатление, что рассказчик подчеркивает количество призывников, апеллируя к традиционным границам между полноправными «воинами» и подневольными данниками «кыштымами».

Аналогичный мотив инкорпорации в состав этнической группы туба представителя сёёка тодош, «пришедшего с Эрчиша» (после падения Ойротского каганата), а также демаркации его потомков туба-тодош от родственников кара-тодош, осевших в долине Урсула, содержит предание № 120 из тома «Несказочная проза алтайцев» [2011, с. 256-257]. Примечательно, что все предания о сёёках, вошедшие в данное издание, за исключением текста № 117 («Ребёнок, родившийся от алмыса») [Там же, с. 250-253], повествуют о родоначальниках в постойротский период, о тех, кто обосновался на территории российской части Алтая после падения каганата. Среди прочих в этой подборке присутствуют достаточно редкие мотивы, фиксирующие память об Ойротской гражданской войне. Так, предки сёёков мандьи-тодош и котон-кыпчак осуждены рассказчиком за то, что «против своего каана воевали» [Там же, с. 262-263]. В предании о кыпчаках зафиксирован мотив угрозы последнего Ойрот-Каана (Амыр-Саны?): «Шотон-кыпчак со своим кааном воевал. Каан испугался, сбежал. Перед тем, как сбежать, каан сказал: “Если вернусь, то отрублю головы всем, кто родился мужчинами, кто родились девушками, груди им отрежу, мучить буду”» [Там же, с. 266-267].

Гражданская война, развязанная претендентами на престол Табачы (Дабачи) и Амыр-Саной, была практически полностью вытеснена из памяти алтайского народа и контекста преданий длительной цинской интервенцией и борьбой с бандитизмом в отсутствие хорошо охраняемых границ [Королёва, 2018]. Однако фольклорные сюжеты фиксируют ее последствия, а именно массовые миграции - как групповые, так и одиночные, отражающие перемещение беженцев в поисках спасения. Так, тексты № 121-129 из упомянутого собрания содержат мотивы инкорпорации полиэтничных беженцев неизвестного происхождения [Несказочная проза алтайцев, 2011, с. 259-269]. 
Механизм инкорпорации развернуто описан в преданиях «Кергилдер», записанных от Анны Чарас-Суйманаковой и Алексея Калкина, из собрания Бронтоя Бедюрова «Озогы Тйӱкилер» [2011, c. 217-226]. «С древних времен и по сей день люди из рода кергил родиной почитают Алтай с голубыми горами», - так звучит зачин из предания Анны Чарас-Суйманаковой. Термин «Алтай» здесь следует понимать расширенно, в значении «легендарная родина», «земля предков». Далее рассказчица описывает образ жизни предков современных кергилов как ремесленников-металлургов и охотников. Она подчеркивает, что ранее кергилы не были скотоводами и не кочевали, «подобно другим алтайцам» [Алтайские исторические предания, 2014, с. 288]. Затем после обобщенного описания годины бедствия чак, следует повествование об Ак-Каме, современнике Ойрот-Каана, среди подвигов которого числится магическое сражение с интервентами «монголами» в долине Короты. Это важная деталь, подчеркивающая причастность к ключевым для алтайского народа историческим событиям. Сын Ак-Кама, охотник-лыжник Йес-Бука, погибает под снежной лавиной в Катунских горах, а его потомки Йес-Казан и Чычканак расселяются в верховьях Катуни, в Бешпельтире и долине Беша, где вступают в административное подчинение зайсану кыпчаков, после чего кергилы и кыпчаки становятся братскими сёёками (кырындаштар). Потомки Чычканака, расселившись по долинам КанЯбагана «стали, наконец, скотоводами» [Там же, с. 291], что знаменует завершение процесса икорпорации в состав алтай-кижи. Далее рассказчица перечисляет все известные алтайские фамилии, происходящие из этого гнезда.

В версии этого предания, записанной от Алексея Калкина, присутствует много знаковых подробностей, позволяющих уточнить происхождение данной линии кергилов. «Местом исхода для родасёёка кергил стала чернёвая тайга Йыш», - начинает Калкин и уточняет: «В Абинской тайге, на берегу Алтын-Кёля селились кергилы, которые произошли от сына знаменитого Тулуну-Бёкё, косатого силача, погребенного стоя» [Алтайские исторические предания, 2014, с. 293]. В версии Калкина мастер (кузнец?) и охотник-лыжник носит имя Тулуну-Бёкё и погибает, спуская лавину, в результате спора с семью алтайскими зайсанами. Залогом спора являются косяки коней, истребует залог после гибели героя его сын Йес-Бука, угрожая ружьем-мультуком жадным зайсанам. После гибели родоначальника семья переселяется «в алтайские земли» Ташту-Боочы, Эки-Нур на берегах Чараса и в Каракольской долине, где постепенно увеличивает поголовье скота и богатеет. Может показаться, что сказитель противопоставляет Аба-Дьиш и Алтай. Но это не так. Алексей Калкин использует термин «Алтай» в локальном значении, например, выражением Ак-Чолушпа алтайда он описывает место рождения героя Агунака, и в том же повествовании использует региональное значение в выражении Ак-кӧбӧк улус Алтайга ананг таркаган [Озогы Тӱӱкилер, 2011, с. 227, 229].

Обращает на себя внимание этномаркирующее описание внешнего облика Тулуну-Бёкё, у которого «было столько волос, что его коса выглядела как настоящий девичий тулун, а не мужская тоненькая косичка кедьеге» [Алтайские исторические предания, 2014, с. 292]. Прическа не характерна для алтайских мужчин, именно поэтому подробно описана, равно как и необычные приемы охоты с опорой на некие «подсказки». А вот дети его потомка Чычканака (в версии Анны Чарас-Суйманаковой) уже острижены как положено, отсюда история с завшивевшой косичкой кедьегезе куртту тас [Озогы Тйӱкилер, 2011, с. 220].

Таким образом, обе версии сходятся в том, что кергилы линии Йес-Буки ведут происхождение изза пределов традиционного для яйлажных скотоводов ареала. С нашей точки зрения, это выходцы из этнического сообщества подтаежных «кузнецких людей», которые составили основу эногенеза современных шорцев и отчасти хакасов и байат-телеутов. Оба рассказчика описывают инкорпорацию большой семьи, восходящей к одному мигранту-родоначальнику, в состав алтай-кижи с принятием наиболее предпочтительного скотоводческого образа жизни, вступлением в административную юрисдикцию российской (Столыпинской) системы зайсанатов и горизонтальные родственные связи с местным населением. Обе версии подчеркивают наличие шаманского дара в этой семье, в первом примере носитель - это Ак-Кам, во втором - предположительно, сам Тулуну-Бёкё и сын Йес-Буки Мыймандык.

С историей гнезда Йес-Буки связано возникновение сразу двух табу, широко известных в наше время среди алтайцев. Во-первых, это запрет на охоту на склонах белков в местах высокой лавинной опасности, где был заживо погребен «косатый силач». Во-вторых, это запрет на охоту на склонах горы Уч-Энмек, где сыновья Мыймандыка убили «маралов Алтай-Ээзи», за что «поплатились» гибелью сородичей и домочадцев [Алтайские исторические предания, 2014, с. 296-297]. Оба запрета сформированы по принципу избыточной предосторожности, который Дж. Даймонд называет «конструктивной паранойей» [Даймонд, 2016, с. 328-329], и возникли в исторически обозримой перспективе. По крайней мере, обе версии предания о кергилах описывают период, когда этих табу еще не существовало. 
Интеграционные сюжеты легли в основу трех преданий: «Зайсан тёлёсов Каака», записанного от внука героя Эрке Ямаева, а также «Гнездо Кульди» и «Гнездо Кёёрчёка», записанных от Ишенера Чапыева. Все три текста имеют общую композиционную структуру. Это расширенная родословная конкретных больших семей (кошунов) с указанием мест расселения после падения Ойрот-Каана, рода занятий и отличительных черт характера ее членов, с обязательным описанием эпизодов участия в ключевых исторических событиях, таких как моление в долине Теренг (1904 г.), «ссылка» (репрессии 1930-х гг.), Великая Отечественная война (1941-1945). Предание о зайсане тёлёсов Кааке в большей степени сконцентрировано вокруг центральной фигуры героя, но тем не менее, как и прочие, явно ставит целью обозначить место описываемой семейной линии в истории Алтая в постойротский период. Рассказчики не случайно подчеркивают обстоятельства освоения нового государственного русского языка, поступления на службу или сотрудничество с русскими биями [Алтайские исторические предания, 2014, с. 264, 265, 267, 271]. Данные тексты - это свидетельство этнического самоопределения в границах нового государства [Там же, с. 268]. Ишенер Чапыев ясно осознает интеграционный посыл и значение повествования, называя процесс восстановления численности народа в составе России јаан учурлу керек ‘большое значительное дело’ [Озогы Тӱӱкилер, 2011, с. 338].

Таким образом, предания демонстрируют нам ряд ключевых маркеров этнической принадлежности - это память об Ойротской войне, яйлажное скотоводство, алтайский язык и закодированное в нем историческое наследие: предания, сказки, нормы и запреты. В настоящей публикации мы не уделили пристального внимания сказочным сюжетам, однако алтаец - это без сомнения тот, кто знает, что на луне сидит людоед Дьелбеген, а в пещере на горе Алмыс-Туу обитают алмысы, нечеловеческие родственники людей из рода алмат. В повседневном общении знание тех или иных традиционных сюжетов и по сей день служит надежным маркером этнической принадлежности. Отсюда постоянное пересказывание преданий в быту представителями разных поколений, в том числе молодыми людьми, которые выросли в урбанизированных условиях, вне стоянок и перекочевок.

Своеобразное восприятие концепта времени у алтайцев, запечатленное в выражении алдында озогы 'вперед в прошлое', является литературным клише, по-видимому, и сформировалось в рамках классической тюрко-монгольской литературной традиции. С точки зрения алтайского языка человек движется вослед прошлому, уходит в историю, оставляя будущее за спиной на волю и промысел своих потомков. Вскоре после смерти он становится героем песен и исторических преданий своего народа, затем - частью обобщенного образа героя легенды (Шуну, Ойрот-Каана, Сартакпая) и даже частью ландшафта (Бабырган, Кёшё-Агач). Продолжая эту линию развития сюжета, следующим уровнем обобщения может стать участие исторического героя в событии космического масштаба, наподобие апокалиптической Кадын-Бий белтиринде чак ‘битвы между Бией и Катунью’. Обращают на себя внимание «говорящие имена» некоторых героев преданий (Шуну, Ескюс-Уул). Традиционная бытовая практика позднего наречения «взрослым» именем (взамен прежнему, детскому) приводит к тому, что герой может быть назван «по аналогии» с существующим литературным персонажем и вместе с именем получить определённый жизненный сценарий (сюжет).

До сих пор событие трехсотлетней давности воспринимается рассказчиками почти как вчерашнее, непосредственно связанное с современными реалиями жизни. На сегодняшний день можно уверенно говорить о принадлежности озогы-куучындар к народной религии алтайцев в качестве апокрифов. Практически каждое повествование «о прежних временах» начинается со слов «мы верим», «по нашей алтайской вере» (Алтай јангыла). «Я верю, [что] Юч-Курбустан, Алтай-Кудай, От-Эне - это Ак Јанг, это моя вера», - утверждает Таныш Бардин и добавляет: «Это наш алтайский буддизм, $я$ думаю». «Наши верят, что на Луне сидит людоед Дьелбеген...», - так начинала рассказ онтологической легенды хранитель музея Сынару Трифанова из с. Теньга. «По нашей вере, камни на перевалах нельзя собирать», - так сообщала культуролог Эркелей Ажанарова из с. Кырлык, предваряя этим замечанием серию быличек о том, что случалось с нарушителями запретов. Фермер-скотовод из с. Боочи Мерген Тохтонов точно так обозначил границы собственной осведомленности в вопросах истории: «Я про археологию не знаю многого, я могу рассказать только о том, во что мы верим» (Полевые материалы Е. В. Королёвой).

В сознании алтайского народа персонажи легенд и преданий живут в буквальном смысле слова: они ушли вперед, в мир героев, но к ним и сейчас можно обратиться, что и происходит всякий раз, когда где-то пересказывают легенду или предание. И они отвечают. Прилет птицы, внезапное изменение погоды и иные приметы позволяют понять и расшифровать ответ из мира героев, который так же, как и наш земной, «солнечно-лунный мир», является частью вселенной (Телекей). В сущности, мы, ныне живущие, не более чем птички на родовых ветках железного Бай-Терека, корни которого глубоки, как сама история. Отсюда это остро актуальное сознание своей преемственности по отно- 
шении к линии предка-прародителя, которое только усугубляется народной трактовкой буддийского учения о перевоплощении: герой возвращается / воплощается через поколения в своем коренном роде / сӧӧк. В современном алтайском сообществе это может порождать сюрреалистический эффект: в случайной беседе ты можешь оказаться среди потомков легендарных баатыров, демичи и зайсанов, образы которых могут быть не менее актуальны для собеседников, нежели их современные социальные роли.

Таким образом, апелляция алтайцев к образам прошлого в поисках справедливости, равно как и «эзопов язык» исторических преданий (по выражению В. А. Шнирельмана), представляются феноменом, идентичным описанной исследователем практике конструирования национальной истории в советский и постсоветский периоды [Шнирельман, 2013, с. 102].

\section{Список литературы}

Алтайские исторические предания ойротской эпохи: XVII - XIX вв. / Гл. ред. и сост. Б. Я. Бедюров; Пер. Е. В. Королевой. Новосибирск: Гео, 2014. 205 с.

Анохин А. B. Материалы по шаманству у алтайцев, собранные во время путешествий по Алтаю в 1910-1912 гг. по поручению Русского Комитета для изучения Средней и Восточной Азии // Сборник Музея антропологии и этнографии при Российской Академии Наук. Л., 1924. T. VI.

Бедюров Б. Алтай-Хангай - вечная Родина / Авт.-сост., гл. ред. Б. Я. Бедюров. Пер. с алт. яз., глоссарий, указатель алтайских топонимов: Б. Я. Бедюров, Е. В. Королева. Поэтические переводы: Е. В. Королева. Закл. ст.: Л. И. Шерстова. М.: Вече, 2017. 432 с.

Даймонд Дж. Мир позавчера. Чему нас могут научить люди, до сих пор живущие в каменном веке / Пер. с англ. А. Александровой. М.: АСТ, 2016. 672 с.

Королёва E. В. Этническая самоидентификация Оймонских старожилов по материалам автобиографических воспоминаний У. М. Аргоковой и С. И. Солонкиной // Актуальные проблемы исторических исследований: взгляд молодых ученых. Новосибирск, 2012. С. 318-326.

Королёва Е. В. Алтайские исторические легенды и предания на рубеже XX-XXI вв.: среда бытования и специфика воспроизводства фольклорных текстов // Языки и фольклор коренных народов Сибири. 2015. № 1 (28). С. 34-40.

Королёва E. B. Алтайские фольклорные сюжеты и параллели в традиционной культуре Уймонских старообрядцев на рубеже XX-XIX веков // Оппозиция «свой-чужой» в языке, фольклоре, литературе, языке, культуре: Материалы Регионального гуманитарного форума научной молодежи. Новосибирск, 2015. C. 75-90.

Королёва Е. В. «Зоны умолчания» алтайских исторических преданий: генезис и эволюция во времени // Языки и фольклор коренных народов Сибири. 2018. № 1 (35). С. 58-65.

Моисеев B. А. Цинская империя и народы Саяно-Алтая: XVIII в. М.: Наука, 1983. 147 с.

Несказочная проза алтайцев / Сост. Н. Р. Ойноткинова, И. Б. Шинжин, К. В. Яданова, Е. Е. Ямаева. Новосибирск: Наука, 2011. 576 с.; илл. + компакт-диск. (Памятники фольклора народов Сибири и дальнего Востока; Т. 30).

Озогы Тӱ̈килер /Алтайские легенды и предания ойротской и царской эпох/. Горно-Алтайск: Алтан-Туу, 2011. $424 \mathrm{c}$.

Чемчиева А. П. Субэтнические группы алтайцев: противоречия и символы этнической идентичности // Новые исследования Тувы. 2017. № 1. С. 135-150.

Шерстова Л. И. Новые идентичности в Южной Сибири // Дневник Алтайской школы политических исследований. 2005. № 21. URL: http://ashpi.asu.ru/studies/2005/shrstva.html

Шнирельман B. А. Излечима ли болезнь этноцентризма? Из опыта изучения конструирования опыта прошлого - ответ моим критикам // Политическая концептология. 2013. № 1. C. 10-113. URL: http://politconcept.sfedu.ru/2013.1/08.pdf 


\section{E. V. Koroleva}

Independent noncommercial organization Scientific and methodical center «Siberia», Novosibirsk, Russian Federation; e.v.koroleva@inbox.ru

\section{Ethnic self-identification of Altay-kizhi in the context of oral historical legends}

The article is devoted to the analysis of ethno-marking and integration plots of Altai historical legends. The author characterizes the historical circumstances of the formation of the corpus of Altai historical legends, attempts to systematize the stories on the content and highlights the signs of ethnic identity for Altai-kizhi on the basis of folklore texts: language, lifestyle, type of management, clothing, hairstyle. A debatable question about ethnic borders of Altai-kizhi and relations with local sub-ethnic groups is presented. The author insists on the incompleteness of the integrative processes taking place in the territory of the Altai Mountains in the post-Oirot period, which currently lead to the inclusion of various small ethnic and sub-ethnic turkic-speaking groups in the Altay-kizhi people. The importance of knowledge of specific folklore subjects, and not only the Altai language for ethnic idetification is emphasized. Historical legends are presented as a marker of ethnic boundaries in a multi-ethnic population. The mechanisms of formation of traditional ethical prohibitions and their significance for the definition of their "own" and "others" are described. The stages of integration of migrants into the structure of exogamous genera of Altay-kizhi are described in detail on the example of the texts of legends. The author illustrates the process of population recovery through incorporation and natural growth and describes the cultural attitudes that allow to preserve ethnic identity after depopulation and civil war. Question of bilingual existence of Altai folklore texts is considered. The relevance of historical legends in the modern community is noted. Thus, folklore texts could be considered not only as examples of folk literature, but also as a source of ethnic history.

Key words: Altai, Altai folk, Altaian historical legends, oral history, ethnic history, Oirot Kaganate, civil war, ethnic identification, incorporation of foreigners, reconstruction of the system of exogamous genera.

\section{References}

Altayskie istoricheskie predaniya Oirotskoy epokhi: XVII-XIX vv. [The historical legends of Altai folk of Oirot state period]. Editor-in-chief and compiler B. Ya. Bedyurov; translated by E. V. Koroleva. Novosibirsk, Geo Publ. House, 2014, 205 p. (in Russ.).

Anokhin A. V. Materialy po shamanstvu u altaytsev sobrannye vo vremya puteshestviy po Altayu v 1910-1912 gg. po porucheniyu Russkogo Komiteta dlya izucheniya Sredney i Vostochnoy Azii [Findings on shamanism from the Altai folk collected during the Altai travels in 1910-1912 on behalf of the Russian Committee for the study of Central and Eastern Asia]. In: Sbornik Muzeya antropologii i etnografii pri Rossiyskoy Akademii Nauk [Collection of the Museum of anthropology and Ethnography at the Russian Academy of Sciences]. Leningrad, 1924, vol. VI. (in Russ.).

Bedyurov B. Altay-Khangay - vechnaya Rodina. [Altay-Khangay - eternal Homeland]. Avtor-sostavitel', gl. Redaktor: B. Ya. Bedyurov. Perevod s altayskogo yazyka, glossariy, ukazatel' altayskikh toponimov: B. Ya. Bedyurov, E. V. Koroleva. Translated by E. V. Koroleva. Zaklyuchitel'naya stat'ya: L. I. Sherstova. Moscow, Veche Publ. House, 2017, 432 p. (in Russ.).

Diamond J. Mir pozavchera. Chemu nas mogut nauchit' lyudi, do sikh por zhivushchie v kamennom veke [The world until Yesterday]. Translated by A. Aleksandrova. Moscow, AST Publ. House, 2016, 672 p. (in Russ.).

Koroleva E. V. Etnicheskaya samoidentifikatsiya Oymonskikh starozhilov po materialam avtobiograficheskikh vospominaniy U.M. Argokovoy i S.I. Solonkinoy [Ethnic identity of the Oimon old residents in the content of autobiographical memories of U.M. Argokova and S.I. Solonkina]. In: Aktual'nye problemy istoricheskikh issledovaniy: vzglyad molodykh uchenykh [Actual problems of historical research: the view of young scientists]. Novosibirsk, 2012, pp. 318-326. (in Russ.).

Koroleva E. V. Altayskie istoricheskie legendy i predaniya na rubezhe XX-XXI vekov: sreda bytovaniya i spetsifika vosproizvodstva fol'klornykh tekstov [Altai historical legends and stories at the turn of XX-XXI centuries: the environment of existence and the specifics of the reproduction of folklore texts]. Yazyki i fol'klor korennykh narodov Sibiri [Languages and folklore of indigenous peoples of Siberia]. 2015, no. 1 (28), pp. 34-40. (in Russ.).

Koroleva E. V. «Zony umolchaniya» altayskikh istoricheskikh predaniy: genezis i evolyutsiya vo vremeni [Zones of silence in the Altai historical legends: genesis and evolution in time]. Yazyki i fol'klor korennykh narodov Sibiri [Languages and folklore of indigenous peoples of Siberia]. 2018, no. 1 (35), pp. 58-65. (in Russ.).

Moiseev V. A. Tsinskaya imperiya i narody Sayano-Altaya v XVIII v. [Tsin Empire and the folks of Altai-Sayan region in XVIII sent.]. Moscow, Nauka Publ. House, 1983, 149 p. (in Russ.).

Neskazochnaya proza altaytsev [Altai folk legends]. Compilers N. R. Oynotkinova, I. B. Shinzhin, K. V. Yadanova, E. E. Yamaeva. Novosibirsk, Nauka Publ. House, 2011. 576 p.; ill. + CD-disk. Pamyatniki fol'klora narodov Sibiri i dal'nego Vostoka [Monuments of Folklore of Peoples of Siberia and the Russian Far East], vol. 30. (in Russ.).

Ozogy Tuukiler. In: Altayskie legendy i predaniya oyrotskoy $i$ tsarskoy epokh [The Altai folk legends and stories of Oirot state period]. Gorno-Altaysk, Altan-Tuu Publ. House, 2011, 424 p. (in Altaian). 
Chemchieva A. P. Subetnicheskie gruppy altaytsev: protivorechiya i simvoly etnicheskoy identichnosti [Sub-ethnic groups of Altai folk: contradictions and symbols of ethnic identity]. Novye issledovaniya Tuvy [The new research of Tuva]. 2017, no. 1, pp. 135-150. (in Russ.).

Sherstova L. I. Novye identichnosti v Yuzhnoy Sibiri [New identities in southern Siberia]. Dnevnik Altayskoy Shkoly Politicheskikh Issledovaniy [The Diary of the Altai school of political studies]. 2005, no. 21. URL: http://ashpi.asu.ru/studies/2005/shrstva.html (in Russ.).

Shnirel'man V. A. Izlechima li bolezn' etnotsentrizma? Iz opyta izucheniya konstruirovaniya opyta proshlogo - otvet moim kritikam [Is the disease of ethnocentrism curable? From experience of studying design experience of the past answer to my critics]. Politicheskaya kontseptologiya [Political conceptology]. 2013, no. 1, pp. 10-113.

URL: http://politconcept.sfedu.ru/2013.1/08.pdf (in Russ.). 